\title{
O Ensino de Filosofia nos meandros do Ensino Médio Estadual
}

\author{
Fernanda de Oliveira Veiverberg'
}

\begin{abstract}
Resumo
A reflexão acerca do ensino de filosofia envolve diferentes questões. No âmbito da educação pública é necessário compreender os meandros que envolvem as práticas escolares, pautadas nos princípios da gestão democrática, e de como as orientações governamentais são compreendidas e executadas dentro da realidade de cada escola. Assim, ensinar filosofia para jovens de Ensino Médio não é algo que deriva, somente, dos anseios dos professores responsáveis pela disciplina, exige uma compreensão crítica da formação que se almeja, do campo de possibilidades que cada instituição de ensino oferece e a prática do diálogo constante, pois se tratando do ambiente escolar pouco se cria e se desenvolve isoladamente ou individualmente. Para isso, os pressupostos da formação humana integral e de práticas pedagógicas interdisciplinares parecem corresponder com a função da filosofia no Ensino Médio em um contexto de reestruturação de currículo, mas também de paradigmas.
\end{abstract}

Palavras-chave: Filosofia; Ensino Médio; Gestão Democrática; Formação Integral.

\section{The philosophy of education in the intricacies of the middle school state}

\begin{abstract}
The reflection about the teaching philosophy involves different issues. Within the framework of public education is necessary to understand the intricacies involving school practices, guided by the principles of democratic management, and how the government orientation are understood and executed within the reality of each school. So teach philosophy to high school youth is not something that derives only the wishes of the teachers responsible for the discipline, requires a critical understanding of the formation which aims, the field of possibilities that each educational institution offers and the practice of constant dialogue, because it comes from the bit school environment is created and developed in isolation or individually. For this, the assumptions of integral human formation and interdisciplinary teaching practices seem to correspond with the function of philosophy in high school in a curriculum restructuring context, but also paradigms
\end{abstract}

Keywords: Philosophy; High school; Democratic management; Integral formation

\footnotetext{
1 Professora de Filosofia da Rede Estadual de Ensino do Rio Grande do Sul. fveiverberg@gmail.com
} 


\section{Introdução}

O desejo diz: "Eu não queria ter de entrar nesta ordem arriscada do discurso; não queria ter de me haver com o que tem de categórico e decisivo; gostaria que fosse ao meu redor como uma transparência calma, profunda, indefinidamente aberta, em que os outros respondessem à minha expectativa, e de onde as verdades se elevassem, uma a uma; eu não teria senão de me deixar levar, nela e por ela, como um destroço feliz". E a instituição responde: "Você não tem por que temer começar; estamos todos aí para lhe mostrar que o discurso está na ordem das leis; que há muito tempo se cuida de sua aparição; que the foi preparado um lugar que o honra, mas 0 desarma; e que, se lhe ocorre ter algum poder, é de nós, só de nós, que ele lhe advém" (FOUCAULT, 1996. p. 6-7).

O presente texto abordará algumas questões que se referem ao ensino de filosofia no ensino médio, mais especificamente, na rede pública de ensino. Para tanto serão apresentadas algumas reflexões provenientes de experiências pessoais dadas neste meio e elementos presentes no contexto da inserção obrigatória da disciplina nos currículos escolares.

Refletir sobre o ensino de filosofia envolve a consideração de diversos elementos, em primeiro lugar de onde parte esta reflexão e qual o seu propósito. Mas também, como esta reflexão se desenvolve e ao que ela se lança. Se fazemos parte daquilo que refletimos ou se olhamos de algum outro plano de investigação, pois se estamos ou não imersos em determinada questão isto afetará nossa compreensão sobre o assunto. Além disto, como esta reflexão se relaciona com o seu contexto, e neste sentido questiona-se sobre sua pertinência, e se a partir da compreensão de problemas existe ou não o desejo de encontrar saídas e opções plausíveis como forma de superar tais situações diagnosticadas.

Desta forma, pensar sobre o ensino de filosofia envolve a compreensão do contexto de inserção desta disciplina, e o enfoque dado neste trabalho é o Ensino Médio, assim como a transparência na concepção teórica e metodológica que se tem como necessária à formação dos jovens estudantes. 
Assim, é importante considerar as políticas públicas direcionadas à reforma e reestruturação do Ensino Médio, e também como a filosofia é concebida neste processo, além de algumas experiências vivenciadas durante a formação acadêmica e em minha própria inserção no ensino público estadual ao longo de três anos de atuação em duas escolas públicas de Santa Maria, Rio Grande do Sul.

Vale mencionar que na prática do ensino de filosofia a reflexão acerca desta deve ser uma constante e a menção ao texto de Foucault evidencia que ao adentrar na ordem do discurso, que não é tarefa fácil, encontramos institucionalizados, por meio das leis, um padrão discursivo oficial, mas ao voltar-se para a questão do ensino de filosofia, percebe-se que cada sujeito possui suas concepções e um modo de agir particular, que dialogam sim com o que está estabelecido, mas que interpreta e oferece forma por meio da ação. Ou seja, em cada realidade escolar diversa, diversas também serão as concepções de ensino e inúmeras as possibilidades de ação transformadora de tal realidade.

\section{Formação inicial e ensino público}

O ponto principal da reflexão sobre o ensino não é a formação específica de quem propõe a reflexão, mas esta se torna relevante no sentido de haver proporcionado o interesse pelo ensino de filosofia e ter sido responsável pelos primeiros contatos com a realidade escolar, efetivando as primeiras impressões sobre estes aspectos. Parece cada vez mais evidente que para o assunto aqui tratado apenas considerações teóricas apontariam para um esgotamento investigativo, refletir sobre o ensino de filosofia na escola pública estadual estando distante em nível de interesse, envolvimento e inserção pode até ser contributivo, mas corre um sério risco de tornar-se um discurso vazio. E cada vez mais, devemos estar atentos e valorizar a formação pessoal que possuímos, pois é muito comum existir professores com as mais diversas formações acadêmicas sendo designados para lecionar a disciplina de filosofia em muitas escolas, mesmo que este tenha muito empenho em sua prática o espaço que estará ocupando é por direito de 
outro indivíduo, e é este espaço que deve ser apropriado pelos professores de filosofia, tornando-os significativos para a realidade escolar em que estão inseridos.

Com formação inicial em história e posteriormente em filosofia sempre me instigou as relações humanas criadas e reformuladas em determinados espaços e tempos. O ambiente educacional é um cenário rico de vivências que refletem o acesso ao conhecimento acumulado, aos valores reproduzidos, aos anseios e problemáticas próprias de um ambiente plural em si mesmo e distinto de outros ambientes semelhantes.

As primeiras experiências e impressões sobre o ensino de filosofia deram-se graças às disciplinas didático/pedagógicas do currículo do curso de graduação em filosofia, considerando que se tratava de uma licenciatura plena e, no entanto, a preocupação com a formação dos futuros professores não atingia o núcleo das disciplinas propedêuticas. Assim, pensando que o currículo em si não motivava grandes aproximações com a realidade escolar e algumas menções inclusive alargavam a distância e o desinteresse dos acadêmicos em relação ao ensino de filosofia e acabava por transformar o exercício de ensinar, algo restrito ao estágio curricular obrigatório e uma atividade pouco almejada pelos futuros formandos.

Vale ressaltar ainda mais este aspecto, pois é comum haver críticas neste sentido provenientes de alunos de diferentes cursos de licenciatura, não sendo, portanto, um problema específico da filosofia. Pode-se mencionar então um certo distanciamento que a academia, em geral, mantém das dimensões externas da realidade na qual se insere. O contato com o restante da sociedade, durante a formação do acadêmico, é direcionado para práticas obrigatórias ou participação em projetos de extensão (quando estes existem). A formação do docente não deve menosprezar esta relação entre a academia e a comunidade a qual ela atende enquanto instituição de ensino, inclusive como critério e modo de averiguar se há demanda para a formação/profissão pretendida e como esta se caracteriza no contexto social, quais suas implicações e problemáticas.

Assim, o ensino acadêmico em si mesmo não é prejudicial ou inadequado, é excelente, desde que busque proporcionar conhecimento e possibilidade de Revista Digital de Ensino de Filosofia - Santa Maria - Ano I - n. 1 - jan./jun. 2015. 
atuação no mundo externo, pois do contrário há um enclausuramento que pode levar a alienação em vários sentidos. Em relação à formação do professor de filosofia, quando não há este direcionamento para a pesquisa e o desenvolvimento de suas concepções e metodologias de ensino, ou quando esta existe, mas não reflete o diálogo com a demanda social existente, os efeitos são vários, de curto e médio prazo.

Muitos estudantes de filosofia não tiveram aulas de filosofia durante sua formação no ensino médio ou tiveram de maneira inadequada e o espelho para sua prática futura ficará restrita ao modo como os professores da graduação ensinavam e, como mencionado anteriormente, o ensino é propedêutico em um modelo bastante formal que não cabe no ensino público para o jovem de ensino médio, uma vez que diferente do aluno de graduação não escolheu estudar filosofia, ele é obrigado a frequentar a escola até a maioridade. É bastante comum durante o estágio curricular de graduação que o acadêmico de licenciatura frustre-se por elaborar uma aula que é inspirada no modelo acadêmico e não surte resultados na realidade escolar, e isto é bastante comum uma vez que os tempos e espaços são outros e o público, mais uma vez vale ressaltar, é bastante distinto.

Quando se está na universidade, ainda que em um curso de licenciatura, nos distanciamos da escola, poucos são os momentos que nos dispomos a retornar para este ambiente. A experiência do estágio é muito construtiva, pois há trocas de informações sobre os momentos presenciados pelos estagiários, auxilio e orientação do professor responsável pela disciplina, realidade que muitas vezes não existe no ambiente escolar, em que não há muitos momentos destinados a trocas de experiência e nem orientações quanto ao planejamento das aulas. Ou seja, o espaço de formação inicial deve ser otimizado, pois é justamente a esse que temos garantia e direito, já que enquanto desenvolvemos nosso trabalho no âmbito das escolas de ensino médio estes espaços são raros ou inexistentes.

Cada vez mais, deve-se reforçar os espaços de formação nos cursos de licenciatura, para que haja uma valorização do trabalho docente. Mais do que nunca é necessário buscar formas de diálogo entre diferentes áreas de 
conhecimento, pois é imprescindível a existência do distanciamento do modelo de "engavetamentos de disciplinas" que existe nas universidades. Este modelo não é apropriado no ambiente escolar, pois o modelo disciplinar é defasado e existe um processo já em andamento de construção das práticas pedagógicas que tenham em vista a formação humana integral, a partir de propostas interdisciplinares e não fragmentadas e isoladas.

\section{Currículo e gestão democrática}

É necessário considerar que a atual presença da disciplina de filosofia nas escolas públicas relaciona-se com o contexto da reestruturação do Ensino Médio, a nível estadual e nacional. É importante mencionar que a prática escolar influencia no modelo que esta orientação tomará, uma vez que este processo de reestruturação se caracteriza de diferentes formas em função da aplicabilidade em diferentes realidades escolares, em parte, devido à questões materiais e em grande medida, devido à ineficiência do modelo de gestão escolar.

Ao iniciar uma investigação sobre questões que tocam profundamente o ambiente escolar, considerando a função da gestão educacional em tal ambiente, é inevitável não acabar por sentir certo receio. Receio de observar mais atentamente a série de meandros que constituem a rotina escolar; receio de descobrir nos discursos proferidos a real intenção dos sujeitos que elaboram a prática educacional, receio de perceber o quanto o conceito de gestão democrática pode ser insuficiente se não houver um sentido de unidade no ambiente escolar.

Se pensarmos na educação como um objeto orgânico, constituído de múltiplas formas, facetas e relações, perceberemos que alguns elementos são fundamentais para o bom funcionamento e para a necessária coesão das práticas escolares. A gestão escolar, nesse sentido, é um destes elementos, mas é também uma espécie de mola propulsora desse processo, ou seja, se a gestão escolar é precária e despreocupada com a qualidade da educação, todo o restante sofrerá as consequências negativas. Se a proposta de gestão escolar, evidenciada em sua 
proposta político pedagógica - PPP - é clara e coerente com os anseios daqueles que pertencem à determinada escola e, portanto, é razão de sua existência, tais sujeitos se sentirão reconhecidos, desde que haja oportunidade para a participação ativa na tomada de decisões, então o funcionamento escolar estará assegurado.

A estrutura curricular não é em si a finalidade do processo educacional, mas é o que oferece os meios para integrar os objetivos presentes no projeto político pedagógico da escola. É o currículo que organiza as práticas educacionais em tempos e espaços específicos, assim como estabelece igualdade entre as diferentes áreas do conhecimento necessárias para uma formação que vise ser integral, isto é, que constitua todas as etapas da vida e campos de interesse humano.

Também pode organizar-se de maneira a priorizar mais algumas disciplinas em detrimento de outras - se isso ocorre por intenção honesta dos que compõem a comunidade escolar, é possível perceber um aspecto positivo, mas se o fato ocorre por descuido, subordinação ou por uma simples questão de comodismo deve-se não apenas desconfiar das intenções, como também, julgar e propor transformações pertinentes.

A estrutura curricular é precedida por leis que oferecem diretrizes e orientações gerais, mas as escolas devem construir em meio a sua comunidade escolar o modelo que seja mais adequado aos anseios dos sujeitos que fazem parte de tal realidade. Geralmente existe um padrão muito evidente de predominância da carga horária semanal destinada às disciplinas de língua portuguesa e matemática, e a justificativa dos professores destas áreas é em relação a grande carga de conteúdos a serem desenvolvidos, bem, neste sentido deve-se lembrar que a filosofia é a "mãe" de outras disciplinas e um dos campos de conhecimento primeiramente desenvolvidos pelos seres humanos. É evidente que temos uma questão de interesses políticos, uma vez, que o IDEB (Índice de Desenvolvimento da Educação Básica) é medido, entre outros itens, como base em provas aplicadas aos alunos com questões de língua portuguesa e matemática, seguindo o modelo 
internacional, como o Sistema Nacional de Avaliação da Educação Básica (SAEB) que "medem" a proficiência nestas áreas, através de provas padronizadas que não respeitam a diversidade cultural, regional e as características de cada escola.

Parece existir uma áurea de conformismo que reside nas práticas escolares, em que alguns princípios de seu funcionamento como a organização curricular, passam despercebidos ou não são questionados. Os currículos poderiam ser desenvolvidos de outra forma, as posturas dos gestores em ampliar a oferta de ensino para além daquilo que é sugerido nos decretos dos órgãos públicos de ensino são essenciais, assim como a possibilidade da comunidade escolar enxergar seus objetivos educacionais nos objetivos da própria escola.

Considerando a leitura de alguns textos oficiais que orientam e legislam as práticas educacionais do país, percebe-se como é evidente a posição a favor da escola assumir suas características particulares em relação à sua própria gestão. Nas Diretrizes Curriculares do Ensino Fundamental e do Ensino Médio para o Sistema Estadual de Ensino através do Parecer n. ${ }^{0323 / 99}$, temos no ponto quatro, referente à qualidade do ensino e currículo, orientações que evidenciam a necessidade das escolas poderem construir internamente o seu projeto curricular:

\begin{abstract}
A alternativa que a LDB elegeu, em relação a formulação do currículo, privilegia a definição de diretrizes curriculares, em oposição à Lei n5.692/71, que determinava que o Conselho Federal de Educação fixaria um núcleo comum. A opção pelas diretrizes curriculares, e não por grupos de matérias permite que o Brasil se alinhe ao lado de um grande número de países que, por meio de reformas educacionais, nos últimos tempos, têm passado a dar maior espaço de decisões às escolas (RIO GRANDE DO SUL. Parecer $\left.n^{\circ} 323 / 99,1999\right)$.
\end{abstract}

No Parecer CNE/CEB n7/2010, que apresenta discussões sobre as Diretrizes Curriculares Nacionais Gerais para a Educação Básica, podemos reforçar a visão que se estabelece acerca da construção curricular como elemento constituinte da Gestão Escolar, uma vez que lemos no ponto "Formas de Organização Curricular" a seguinte passagem: 


\begin{abstract}
A matriz curricular constitui-se no espaço em que se delimita o conhecimento e representa, além de alternativa operacional que subsidia a gestão de determinado currículo escolar, subsídio para a gestão da escola (organização do tempo e espaço curricular; distribuição e controle de carga horária docente) e primeiro passo para a conquista de outra forma de gestão do conhecimento pelos sujeitos que dão vida ao cotidiano escolar, traduzida como gestão centrada na abordagem interdisciplinar. Neste sentido, a matriz curricular deve se organizar por "eixos temáticos", definidos pela unidade escolar ou pelo sistema educativo (MINISTÉRIO DA EDUCAÇÃO. Parecer CNE/CEB n7/2010).
\end{abstract}

Por meio de atividades de pesquisa, realizadas anteriormente, em escolas públicas da cidade de Santa Maria, Rio Grande do Sul, foi possível observar que a LDB (Lei Federal n 9.394, de 20/12/96 que Estabelece as Diretrizes e Bases da Educação Nacional) serve como base na elaboração do projeto político pedagógico e algumas vezes os dois até se confundem - onde deveria haver uma orientação existem cópias. Assim, não é possível perceber o interesse por buscar algo novo, que corresponda e se aproxime efetivamente da realidade escolar, há sim o desejo de algo que seja definitivo e que não corra o risco de fracassar. A LDB, dessa forma, é o que norteia toda a organização dos níveis escolares e o projeto das escolas, e serve inclusive, como orientação para a elaboração dos currículos. Em algumas situações, nem ao menos faz referência às características peculiares do processo interno de ensino-aprendizagem, o que faz parecer que tal projeto poderia ser aplicado à realidade de qualquer outra escola, já que não se relaciona com nada em especial.

De acordo com Santos (2002), essa situação é típica nos quadros sociais em que a democracia se estabelece, devido a falta de reconhecimento entre representantes políticos e a população, também pela falta de engajamento nas causas coletivas.

Quanto mais se insiste na fórmula clássica da democracia de baixa intensidade, menos se consegue explicar o paradoxo de a extensão da democracia ter trazido consigo uma enorme degradação das práticas democráticas. Aliás, a expansão global da democracia liberal coincidiu com uma grave crise que ficou conhecida como a da dupla patologia: a patologia da participação, sobretudo em vista 
do aumento dramático do abstencionismo; e a patologia da representação, o fato de os cidadãos se considerarem cada vez menos representados por aqueles que elegeram (SANTOS, 2002. p. 3).

Nesse sentido, Veiga (2001, p.13) afirma que se perde o "processo permanente de reflexão e discussão dos problemas da escola, na busca de alternativas viáveis à efetivação de sua intencionalidade, possibilitando a vivência democrática necessária para a participação de todos os membros da comunidade escolar". A elaboração de planos de aula, de propostas de estudo e de grupos de trabalho deve ser autêntica, os sujeitos envolvidos devem sentir entusiasmo em suas ações, ter disponibilidade, envolvimento e criatividade. Devem saber que nem sempre os objetivos são alcançados, as hipóteses comprovadas e os resultados satisfatórios; em um ambiente escolar, tratando do processo de ensino, qualquer efeito intencional é válido, qualquer mudança é bem vinda.

A gestão democrática afirma a autonomia da instituição escolar e a democratização do ensino, é uma forma de combater o modelo de organização escolar baseado na Administração Escolar, excessivamente burocrática, disciplinadora e hierárquica. O envolvimento democrático, de participação efetiva, no que se refere à participação em conselhos, reuniões pedagógicas, planejamentos curriculares e elaboração do projeto político pedagógico, requer interesse pela realidade escolar e consciência das finalidades da escola, sua intencionalidade educativa, sua estrutura organizacional (administrativa e pedagógica), ou seja, as características da escola em si.

Para realizar um ensino de qualidade e cumprir suas finalidades, as escolas têm que romper com a atual forma de organização burocrática que regula o trabalho pedagógico - pela conformidade às regras fixadas, pela obediência a leis e diretrizes emanadas do poder central e pela cisão entre os que pensam e executam - que conduz à fragmentação e ao consequente controle hierárquico (VEIGA, 2001, p. 26).

É demasiadamente importante o fortalecimento de espaços de discussão no meio escolar em que se tenha a liberdade de levantar questões coletivas, propor 
mudanças e argumentar em relação a um caminho a ser seguido. No entanto, o que é bastante presente nas escolas são momentos de encontro de representantes dos segmentos escolares, que nem sempre falam pelo todo, ou expressam a vontade da maioria.

Pelo estilo democrático, procura-se criar um ambiente em que as pessoas se sintam à vontade para expressar suas ideias e visões, experimentar novas ações e criar novos projetos. As pessoas em todos os ambientes de atuação são encorajadas e apoiadas a expressar-se acerca de suas ideias e opiniões sobre o trabalho escolar e tomar iniciativas correspondentes. (LUCK, 2012. p.79)

Exemplos corriqueiros desse fato são as reuniões de pais em que, por diversas razões, há uma participação ínfima dos mesmos, ou até mesmo em conselhos participativos, em que se reúnem professores e alunos para discutir questões relacionadas ao decorrer do ano letivo e a presença dos alunos se restringe aos líderes de turma ou integrantes do grêmio estudantil (quando este existe na escola). A grande maioria da comunidade escolar parece não ter um interesse genuíno pela integração e participação nas decisões e transformações da escola. Dessa forma, é necessário que os gestores tenham por objetivo motivar tal participação e oferecer meios para que isso ocorra. Segundo Lück, o gestor deve exercer uma liderança positiva (ainda que não se deseje uma organização hierarquizada):

Liderança é, pois, um conceito complexo que abrange um conjunto de comportamentos, atitudes e ações voltado para influenciar pessoas e produzir resultados, levando em consideração a dinâmica das organizações sociais e do relacionamento interpessoal e intergrupal no seu contexto, superando ambiguidades, contradições, tensões e dificuldades por ele enfrentados, o seu sucesso se assenta sobre seu entusiasmo proativo, orientado por valores educacionais consistentes e sólidos, tendo como foco o desenvolvimento de uma cultura de aprendizagem significativa na escola. (ibid. 2012. p. 37)

Ao questionar a estrutura escolar deve-se ter clara a noção de que esta possui uma identidade e cultura única, resultado da história de sua formação e da ação dos sujeitos participantes do processo. Para além da realidade da escola, existe um mundo que é comum a todos; ainda que existam diferenças que firmam 
os sujeitos como indivíduos, o conjunto que compõem sua "bagagem cultural". Existe também um contexto no qual nos encontramos que é repleto de informações, onde a velocidade é um critério fundamental e onde a tecnologia já ultrapassou os limites espaciais. É imprescindível o reconhecimento dessa realidade e a articulação da abordagem desta, de forma a possibilitar o reconhecimento de tal contexto também para o aluno, pois somente dessa maneira será possível o diálogo crítico. Nesse sentido, o texto de Tomazetti e Gallina (2009) destaca a importância da compreensão do contexto contemporâneo e da cultura jovem.

Torna-se importante atentar para as condições culturais contemporâneas, em que estão inseridos os estudantes/jovens. É urgente compreender a condição da cultura contemporânea calcada nas novas tecnologias da informação e da comunicação, na cultura do consumo e na mídia (TOMAZETTI, E. GALLINA, S. 2009, p. 174).

Desta forma, o ensino de filosofia não pode estar desatrelado de seu contexto escolar, social e cultural. Deve existir diálogo com outras disciplinas e conhecer a organização escolar, percebendo que é possível refletir sobre a prática visando modificações e adequações ao ambiente em que nos encontramos.

É muito comum as perguntas em relação a "função" da disciplina de filosofia no ensino médio, a pergunta é feita, sobretudo, por alunos que não tiveram aulas de filosofia anteriormente. O questionamento se dá por duas razões, em primeiro lugar porque a dúvida é sincera, tais alunos têm o desejo de saber mais sobre a disciplina e como esta poderá dialogar com seus anseios por conhecimento; a segunda razão é a existência de um hábito entre a população de atrelar pouca importância à educação em geral, e à filosofia mais especificamente, pois estas não são vistas como algo vantajoso em nosso meio, "se não trás um benefício imediato, de preferência material, não deve ser valorizado", esse é um pensamento bem comum e bastante difundido pela mídia que atua como formadora de opiniões e que acaba sendo recurso de informações predominante da qual a população tem acesso, é interesse dos meios de comunicação servir ao poder e este deseja manter o consumismo e materialismo 
entre os cidadãos, para que acreditem que só serão felizes ao comprar certos objetos e com isto dispersam a atenção dos reais problemas existentes na nossa sociedade. A educação filosófica serve para que as pessoas se tornem leitoras de seu meio de convívio, reflexivas quanto aos problemas percebidos e críticas em suas análises e consciente de suas práticas.

\section{Ciências Humanas e a Filosofia}

A área de conhecimento das Ciências Humanas e suas Tecnologias possui um caráter bastante particular no que se refere à relação entre os conteúdos exigidos e a possibilidade de relação com o mundo contemporâneo e vivido pelos alunos. Destaca-se o Plano Nacional de Educação (PNE) instituído pela Lei n 13.005, de junho de 2014, e que deve vigorar de 2014 a 2024. Em relação ao currículo, deve-se mencionar a elaboração das Diretrizes para o Ensino Médio DCNEM (BRASIL, 2012) e, ainda no âmbito avaliativo, a existência do Exame Nacional do Ensino Médio. Tal menção às DCNEM e ao ENEM é relevante, pois a partir de ambos, houve uma configuração das ciências humanas como dimensão norteadora de ações curriculares para o ensino médio, visando abordagens que ampliem a relação de diálogo entre seus componentes, por meio de práticas pedagógicas e considerações sobre avaliação com foco na interdisciplinaridade e na integração curricular.

Cabe ainda à área de Ciências Humanas construir a reflexão sobre as relações entre a tecnologia e a totalidade cultural, redimensionando tanto a produção quanto a vivência cotidiana dos homens. Inclui-se aqui o papel da tecnologia nos processos econômicos e sociais e os impactos causados pelas tecnologias sobre os homens, a exemplo da percepção de um tempo fugidio ou eternamente presente, em decorrência da aceleração do fluxo de informações (Parâmetros Curriculares Nacionais, p. 9). 
O que se apresenta como um diagnóstico acerca dos currículos escolares distancia-se do modelo almejado em uma formação humana integral. Em geral, os currículos são fragmentados e descontextualizados, por vezes, alienantes. As disciplinas seguem mantendo seu modelo tradicional, voltadas para sua lógica interna, com conteúdos introdutórios e propedêuticos. Ou seja, não se orientam para a compreensão e intervenção do papel do indivíduo na sociedade.

Percebe-se que esta fragmentação do saber é um reflexo da formação acadêmica que utiliza de práticas engessadas e cristalizadas. Nesse sentido os conteúdos das disciplinas não atingem os objetivos e as necessidades de inserção crítica na sociedade destes sujeitos. A proposta da organização curricular por áreas de conhecimento visa superar, ainda que inicialmente, a fragmentação do saber por disciplinas. Desta forma, os conceitos estruturantes, "trabalho, cultura, ciência e tecnologia", norteiam a formação humana integral. Espera-se, portanto, integrar no currículo conceitos, conteúdos e temáticas que permitam a compreensão da totalidade do social, para que contribua na formação do estudante, ampliando sua visão de mundo e pretendendo desfragmentar os conteúdos, desenvolver sua criticidade das relações sociais.

A interdisciplinaridade e a contextualização são estratégias que tem como objetivo organizar o currículo, criando alternativas em vista às necessidades de compreensão da realidade. Deste modo, é necessário definir temas ou problemas que perpassem os campos de conhecimento de diferentes componentes curriculares, possibilitando a elaboração de projetos interdisciplinares de pesquisa. Como exemplo prático, é possível citar a construção de projetos por áreas de conhecimento que partam de temas e conceitos relacionados aos conteúdos disciplinares.

Como sugestões ou saídas para tais obstáculos, pode-se mencionar a remodelação dos cursos de formação para professores, desde a formação inicial viabilizando o contato com outras áreas e campos de conhecimento, a construção de espaços e tempos para planejamento e efetivação de uma prática pedagógica coletiva. A formação de grupos de estudos no ambiente escolar como 
tentativa de desalojar e desacomodar a cultura do individualismo e superar o ceticismo em relação às políticas públicas.

Em relação a obrigatoriedade da filosofia como componente curricular e sua institucionalização no Ensino a partir da Lei $n^{\circ} 11.684$ de 2008 que garante a permanência também da sociologia nas escolas, vale algumas menções. A sua institucionalização causa certo incômodo, pois um conhecimento que deve servir para tornar os estudantes mais críticos e reflexivos, se a serviço do uma política pública, deixam seus objetivos um tanto confusos. Kohan (2009) aborda as questões do valor que a filosofia adquire quando se transporta para o rol disciplinas obrigatórias e acaba por servir às políticas do Estado tanto na proposta de formação de cidadãos críticos quanto da manutenção de valores.

Os discursos de "educação para a cidadania", "formação para a democracia", "capacitação para o mercado de trabalho" se inscrevem nos mais variados registros e níveis. $O$ ensino de filosofia usualmente acompanha esses discursos como uma boa estratégia para alcançar estes fins. No Brasil, foi o principal argumento para que - a partir de 2008, fosse introduzida em todas as escolas do País a obrigatoriedade da filosofia como disciplina na grade curricular dos três anos do ensino médio. De modo geral, é bastante usual encontrar como argumento para apoiar o ensino de filosofia na escola que ela contribui a um jogo de finalidades econômicas, sociais, políticas, em ultima instância, não estritamente filosóficas (KOHAN. 2009, p. 71).

Dessa forma, ensinar e aprender filosofia são possibilidades de transformar o pensamento e com isso também o nosso modo de vida sem definir uma forma específica desta transformação. Segundo Kohan (2009, p. 83), a filosofia não transforma uma ordem social para instituir outra, mas transforma o que somos e 0 modo como nós nos pensamos em uma ordem social dada para abrir a possibilidade de pensar e viver uma nova ordem. Nesse sentido ela é revolucionária sem estar a serviço de alguma revolução específica.

A escola de Ensino Médio passou por muitas mudanças significativas nos últimos quinze anos, que ampliaram a diversidade de jovens que hoje a frequentam. Com isso muitos desafios inevitáveis apresentaramse aos professores: como conviver com jovens/adolescentes que veem o mundo de formas distintas devido a influências também desiguais, como aquelas geradas pelas crenças religiosas, os 
costumes locais, as trajetórias familiares, as heranças étnicas, etc. É preciso, pois, encontrar novas formas de desenvolver os conteúdos curriculares, de maneira que os alunos consigam assimilar, em seus próprios mundos, os saberes da escola, auxiliar na construção de formas de convivência pacíficas no ambiente escolar, fazendo com que a diversidade crescente não implique na incapacidade para $\circ$ diálogo e o entendimento entre grupos que habitam 0 mesmo espaço (TOMAZETTI , 2012. p. 21).

Portanto, antes de qualquer organização curricular e decisões em relação à oferta facultativa ou obrigatória de disciplinas como modos de tematizar e esquematizar a realidade, assim como a organização e forma com que o espaço escolar acolhe os estudantes e professores, é de fundamental importância um trabalho coeso da gestão escolar junto com a sua comunidade escolar, para que busquem elementos, conteúdos e ações de fato representativos, que a interdisciplinaridade não seja apenas uma meta distante a ser alcançada e que a formação integral seja a direção tomada.

Acredito que podemos afirmar que dominamos determinado assunto filosófico quando transpomos aquilo que aprendemos para aquilo que se objetiva ensinar, pois é um modo de transformar a informação em conhecimento, e o estudante que faz parte deste processo como sujeito protagonista é instigado a fazer o mesmo, a partir das informações apresentadas, aprofundar suas opiniões através de um processo investigativo e de reconstrução das ideias obtidas através de algum recurso que proporcione a compreensão e principalmente a criação. Este último elemento é o que torna a aprendizagem, de fato, significativa.

\section{Conclusão}

De forma alguma o assunto aqui tratado estará esgotado ao fim deste breve texto, uma vez que o período que vivencia-se nas escolas de ensino médio permitem grandes reflexões e diversas possibilidades de ação, e torna-se um rico campo para um despertar filosófico, na medida em que não há a necessidade de deter a atitude filosófica somente ao espaço da sala de aula e nem tampouco 
somente ao tempo disponível no período letivo. A viabilidade da expansão da filosofia no ensino médio se aproxima dos anseios por uma formação humana integral e está próxima da visão interdisciplinar, que para muitos professores é uma mera utopia.

A educação toma sentido nas práticas escolares e no sentido de reconhecimento dos sujeitos a ela pertencentes. O tema se torna ainda mais pertinente diante do impasse estabelecido nas escolas entre as sugestões pouco articuladas de projetos e currículos e o interesse dos alunos cada vez mais controversos aos olhares daqueles que não são admiradores das mudanças. Como poderá entre um grupo de jovens fazer sentido a prática escolar limitadora de espaços, tempos e saberes?

Atualmente dos professores de filosofia que já lecionam nas escolas, chegam críticas quanto à reação dos alunos e também quanto à superficialidade dos conteúdos propostos pelas orientações do governo. Por parte dos alunos de Ensino Médio, percebe-se as dúvidas quanto à função real de tal disciplina no currículo. Já os alunos de graduação, futuros professores afirmam o caos do ensino sem, muitas vezes, conhecer a realidade escolar. Ou seja, é um tema que envolve diferentes dimensões, mas todas as perspectivas demonstram que há um anseio por dotar de sentido o tema aqui abordado, o ensino de filosofia, que no ambiente escolar não se encontra isolado, está envolto a diferentes elementos que interferem e influenciam nas possibilidades e expectativas almejadas.

\section{Referências Bibliográficas}

BRASIL. Lei de diretrizes e bases da educação nacional n 9394/96. Brasília, 1996.

Decreto de lei $n$. 11.684 de 2 de 2008. Disponível em: <http://www.planalto.gov.br/ccivil_03/_Ato2007-2010/2008/Lei/L11684.htm>. Acesso em: 24 nov. 2010.

BRASIL. Ministério da Educação. Secretaria de Educação Média e Tecnológica. Parâmetros Curriculares Nacionais (Ensino Médio). Brasília: MEC, 2000. CONSELHO NACIONAL DE EDUCAÇÂO, Câmara de Educação Básica. Parecer n. $15 / 98$ 
- Diretrizes Curriculares Nacionais para o Ensino Médio. Brasília: 1998.

CONSELHO NACIONAL DE EDUCAÇÂO, Câmara de Educação Básica. Resolução n. ${ }^{\circ}$

03/98 - Institui as Diretrizes Curriculares Nacionais para o Ensino Médio. Brasília: 1998.

FOUCAULT, Michel. A Ordem do Discurso. São Paulo: Edições Loyola, 1996.

GALLO, Silvio; KOHAN, Walter. A Filosofia no ensino médio. Petrópolis: Vozes, 2000, V.6.

GALLO, Sílvio. Foucault: (Re) pensar a Educação. In: VEIGA-NETO. Alfredo. Foucault e a Educação. $3^{a}$ Edição. Belo Horizonte. Autêntica Editora, 2011.

KOHAN, Walter Omar. Filosofia: o paradoxo de aprender e ensinar. Tradução Ingrid Müller Xavier. Belo Horizonte: Autêntica Editora, 2009.

LÜCK. Heloísa. Liderança em Gestão Escolar. Série Cadernos de Gestão Vol. IV. $8^{a}$ Edição. Petrópolis: Vozes, 2012.

MINISTÉRIO DA EDUCAÇÃO. Orientações Curriculares para o Ensino Médio. Brasília: Ministério da Educação Secretaria de Educação Básica, 2006.

Parecer CNE/CEB n7/2010. Diretrizes Curriculares Nacionais Gerais para a Educação Básica. Brasília: Ministério da Educação Secretaria de Educação Básica, 2010.

RIO GRANDE DO SUL, Conselho Estadual de Educação. Parecer n. ${ }^{\circ 323 / 99}$ Diretrizes Curriculares do Ensino Fundamental e do Ensino Médio Para o Sistema Estadual de Ensino. Porto Alegre: 1999.

SANTOS, Boaventura de Souza, AVRITZER, Leonardo. Democratizar a Democracia. In: SANTOS, Boaventura de Souza (org.). Reinventar a Emancipação Social: Para Novos Manifestos. Rio de Janeiro: Civilização Brasileira, 2002.

SECRETARIA DA EDUCAÇÃO DO RIO GRANDE DO SUL. Proposta Pedagógica para - Ensino Médio Politécnico e Educação Profissional Integrada Ao Ensino Médio. 2011-2014.

TOMAZETTI, Elisete. GALLINA, Simone. Territórios da prática filosófica. Santa Maria: Editora UFSM, 2009

TOMAZETTI, Elisete. Os sentidos do Ensino Médio: Olhares juvenis sobre a escola contemporânea. São Leopoldo: Oikos, 2012.

VEIGA, Ilma Passos A. Projeto Político-Pedagógico da Escola: Uma Construção Possível. SP, Campinas: Papirus, 2001. 